\title{
Memecylon edule leaf extract mediated green synthesis of silver and gold nanoparticles
}

\author{
This article was published in the following Dove Press journal: \\ International Journal of Nanomedicine \\ 20 June 2011 \\ Number of times this article has been viewed
}

\section{Tamizhamudu Elavazhagan \\ Kantha D Arunachalam \\ Centre for Interdisciplinary Research, Directorate of Research, SRM University, Kattankulathur-603203, \\ Tamilnadu, India}

Correspondence: Tamizhamudu Elavazhagan

Centre for Interdisciplinary Research, SRM University, Directorate of Research, SRM University, Kattankulathur-603203,

Tamilnadu, India

Tel +9l 44274 I 7I44

Email tamilamudu@gmail.com
Abstract: We used an aqueous leaf extract of Memecylon edule (Melastomataceae) to synthesize silver and gold nanoparticles. To our knowledge, this is the first report where $M$. edule leaf broth was found to be a suitable plant source for the green synthesis of silver and gold nanoparticles. On treatment of aqueous solutions of silver nitrate and chloroauric acid with $M$. edule leaf extract, stable silver and gold nanoparticles were rapidly formed. The gold nanoparticles were characterized by UV-visible spectroscopy, scanning electron microscopy (SEM), transmission electron microscopy (TEM), energy dispersive X-ray analysis (EDAX) and Fourier transform infra-red spectroscopy (FTIR). The kinetics of reduction of aqueous silver and gold ions during reaction with the $M$. edule leaf broth were easily analyzed by UV-visible spectroscopy. SEM analysis showed that aqueous gold ions, when exposed to $M$. edule leaf broth, were reduced and resulted in the biosynthesis of gold nanoparticles in the size range 20-50 nm. TEM analysis of gold nanoparticles showed formation of triangular, circular, and hexagonal shapes in the size range $10-45 \mathrm{~nm}$. The resulting silver nanoparticles were predominantly square with uniform size range 50-90 $\mathrm{nm}$. EDAX results confirmed the presence of triangular nanoparticles in the adsorption peak of $2.30 \mathrm{keV}$. Further FTIR analysis was also done to identify the functional groups in silver and gold nanoparticles. The characterized nanoparticles of $M$. edule have potential for various medical and industrial applications. Saponin presence in aqueous extract of $M$. edule is responsible for the mass production of silver and gold nanoparticles.

Keywords: Memecylon edule, nanoparticles, bioreduction, electron microscopy, FTIR

\section{Introduction}

Medicinal plants play a major role in the discovery of new therapeutic agents for drug development. Memecylon edule is a shrub or small tree with medicinal properties belonging to the family Melastomataceae. ${ }^{1-4}$ It is commonly known as iron wood tree (English) and puvai kaya (Tamil). ${ }^{5}$ The leaves of this plant have been employed in the dyeing industry to dye wool and silk. ${ }^{6,7}$ Medicinal substances found in plants are referred to as secondary metabolites or biologically active compounds. Some of the bioactive compounds present in M. edule include triterpenes, tannins, and flavonoids. ${ }^{8}$

The leaves of $M$. edule have been reported to possess strong astringent properties and have also been used to treat leucorrhea and gonorrhea in India. A lotion prepared from the leaves is used to treat bruises and cure eye ailments. This plant is also used to treat several conditions and diseases including wounds and diabetes. ${ }^{9,10}$ In the past decade, green nanoparticle synthesis has evolved into an important branch of nanotechnology because of its potential application in the biomedical, magnetics, energy science and aerospace industries. Large amounts of nanoparticles can be easily synthesized from plants and submit your manuscript $\mid$ www. dovepress.com

Dovepress

http://dx.doi.org/10.2147/IJN.SI8347 
the majority of these are nontoxic. ${ }^{11-13}$ They have been used in pharmaceutical drug-based industries to treat B-chronic lymphocytic leukemia, for detecting DNA, to inhibit bacteria and fungi, and to prevent burns and open wound infections. ${ }^{14-16}$ Several techniques, such as chemical, electrochemical, radiation, photochemical, and biological, have been used for the biosynthesis of silver and gold nanoparticles. ${ }^{17}$

In many previous reports, green synthesis of nanoparticles was done in conical flasks utilizing $\mathrm{H}_{2} \mathrm{O}$ as a solvent. ${ }^{18}$ The bioreduction of silver and gold nanoparticles from silver and chloroaurate ions due to their surface plasmon resonance (SPR) has been achieved using plants such as tamarind. ${ }^{19}$ Helianthus annus, Basella alba, Cinnamomum camphora, ${ }^{20,21}$ alfalfa, ${ }^{22}$ Capsicum annuum, ${ }^{23}$ Avena sativa, ${ }^{24}$ Azardirachta indica, ${ }^{25}$ and Pelargonium graveolens, ${ }^{26}$ have been reported for the presence of saponin. Due to the various medicinal properties of $M$. edule, thus commercial production of the saponin is quite high and thereby shows potential for the commercial synthesis of nanoparticles. In this study we describe for the first time, the $M$. edule leaf extract mediated biosynthesis of silver and gold nanoparticles. The silver and gold nanoparticles are of variable sizes, shapes, and chemical composition. ${ }^{27,28}$ In this study, we show that an extract of $M$. edule, placed in a concentrated aqueous solution of $\mathrm{AgNO}_{3}$, resulted in the reduction of the silver ions and formation of silver nanoparticles, and that an extract in aqueous solution of $\mathrm{AuCl}_{4}$ resulted in the reduction of the gold ions and formation of gold nanoparticles. UV-visible (UV-vis) spectroscopy, transmission electron microscopy (TEM), scanning electron microscopy (SEM), energy dispersive X-ray analysis (EDAX), and Fourier transform infra-red spectroscopy (FTIR) were used to examine size and shape of gold and silver nanoparticles in aqueous extract of $M$. edule.

\section{Materials and methods}

Chemicals used for synthesis of silver and gold nanoparticles were chloroauric acid $\left(\mathrm{HAuCl}_{4}\right)$ and silver nitrate $\left(\mathrm{AgNO}_{3}\right)($ Sigma-Aldrich, MO). Fresh M. edule leaves collected from the Potheri forest located at SRM University, (Kattankulathur, Tamil Nadu, India) were used as a plant source for green nanoparticle synthesis.

Equipment including an Orbitol shaker (Labquake shaker; Labindustries, Berkeley, CA) and a PerkinElmer spectrophotometer (Boston, MA) were used initially for nanoparticle synthesis. Nanoparticles size was confirmed by using TEM (1200 EX; JOEL USA, Inc, Peabody, MA) and SEM (FEI Quanta FEG 200; FEI Company, Hillsboro, OR) with high and low vacuum. The functional groups in the synthesized nanoparticles were confirmed by using FTIR (6700 spectrum; Thermo Nicolet, Madison, WI).

\section{Preparation of $M$. edule leaf extract}

Leaves were thoroughly washed and dried completely in the shade. Leaf material was cut into small pieces and powdered in a mixer. Dried powder (20.0 g) of M. edule leaf was added to $100 \mathrm{~mL}$ of sterile distilled water in a $500 \mathrm{~mL}$ Erlenmeyer flask and then boiled for 5 minutes. The flasks were kept under continuous dark conditions at $30^{\circ} \mathrm{C}$. The extract was filtered and stored at $4^{\circ} \mathrm{C}$ for further experiments.

\section{Green synthesis of silver and gold nanoparticle using leaf extract}

The aqueous leaf extract of M. edule was used for the bioreduction process. To synthesize nanoparticles from $M$. edule 5,10 , and $15 \mathrm{~mL}$ of aqeous leaf extract were carefully added to $10 \mathrm{~mL}$ of $1 \mathrm{mM}$ aqueous $\mathrm{AgNO}_{3}$ and $\mathrm{HAuCl}_{4}$ solution in $250 \mathrm{~mL}$ Erlenmeyer flasks. The flasks containing extract were incubated in a shaker at $150 \mathrm{rpm}$ in dark conditions.

\section{UV-vis adsorbance spectroscopy analysis}

The bioreduction (by $\mathrm{AgNO}_{3}$ or $\mathrm{HAuCl}_{4}$ ) of nanoparticles was monitored periodically by UV-vis spectroscopy. The samples used for analysis were diluted with $2 \mathrm{~mL}$ deionized water and subsequently measured by the UV-vis spectrum at regular different time intervals (Raut Rajesh et al). ${ }^{30} \mathrm{~A}$ UV-vis spectrograph of the colloidal solution of silver and gold nanoparticles was recorded as a function of time by using a quartz cuvette with water as reference. The UV-vis spectrometric readings were recorded at a scanning speed of 200 to $800 \mathrm{~nm}^{29}$

\section{TEM analysis of gold nanoparticles}

The precipitate were settled down after the reaction time in the bottom of a conical flask. The suspension above the precipitate containing silver and gold nanoparticles of M. edule was sampled by TEM analysis. TEM samples were prepared by placing a drop of the suspension of silver and gold nanoparticle solutions on carbon-coated copper grids and allowing water to evaporate. The samples on the grids were allowed to dry for 4 minutes. The shape and size of gold nanoparticles from $M$. edule were determined from TEM micrographs.

\section{SEM analysis of silver and gold nanoparticles}

The prepared silver and gold nanoparticles were characterized using high resolution SEM analysis. The samples were 
prepared by simple drop coating of the suspension of silver and gold solutions onto an electric clean glass and allowing the solvent (water) to evaporate. The samples were left to dry completely at room temperature.

\section{FTIR spectroscopy analysis of dried biomass after bioreduction}

A carefully weighed quantity of the synthesized gold and silver nanoparticle powder was subjected to FTIR analysis. The bioreduced chlorauric and silver solution was centrifuged at 10,000 rpm for 15 minutes and the pellet was washed three times with $20 \mathrm{~mL}$ of deionized water. The resulting purified suspension was completely dried and ground with $\mathrm{KBr}$ pellets and analyzed by FTIR. In order to obtain good signal/noise ratio, 512 scans were recorded.

\section{EDAX spectrum measurements}

M. edule leaf extract-reduced gold and silver solutions were dried, drop coated on to carbon film, and tested using EDAX analysis (S-3400N; Hitachi, Tokyo, Japan).

\section{Results and discussion Green synthesis of silver nanoparticles by $M$. edule leaf}

The aqueous extracts obtained from $M$. edule were used for preliminary phytochemical screening for secondary metabolites. The water extract of leaf of $M$. edule gave positive result for saponin and results suggested that saponin is the most favorable starting material to make nanoparticles. Saponin has several medicinal properties and pharmacological activities have been reported in saponins from many other plant species. Triterpene saponin from Ganoderma atrum has hypolipidemic, antiatherosclerotic, anticoagulant, antihypertensive, antimicrobial, hepatoprotective, and immunomodulation properties. Early studies demonstrated that the saponin-based nanoparticles extracted from aqueous extract of Panax ginseng has strong activity for upregulation of immune response in mice. ${ }^{30}$

The kinetics of reduction of aqueous silver and chloroaurate ions during reaction with the $M$. edule leaf extract were easily analyzed by UV-visible spectroscopy. The optical adsorption $U V-v$ is spectra of silver nanoparticles produced by different amounts $(5,10,15 \mathrm{~mL})$ of the dried biomass of aqueous leaf extract of M. edule. The result shows the production of silver nanoparticles within 3 hours after silver ions came in contact with the biomass. The addition of $M$. edule leaf extract to the aqueous $\mathrm{AgNO}_{3}$ solution resulted in the color of the solution changing to dark brown due to the SPR. The color changes

were noticed because of the production of silver nanoparticles. Comparative experiments were carried out to examine the effect of different amounts of M. edule leaf extract (5, 10, and $15 \mathrm{~mL}$ ) on bioreduction of silver ions (Figure 1).

It is well-known that these results are supported in previous reports, where the addition of aqueous leaf extract of various plants to $10^{-3} \mathrm{M}$ aqueous $\mathrm{AgNO}_{3}$ solution started its color change due to the excitation of SPR in the production of silver nanoparticles. ${ }^{18,31}$ Figure 2 clearly shows the strong adsorption peak at $0.51(\mathrm{AU})$ over increasing time of reaction by gently reducing $\mathrm{AgNO}_{3}$ with $15 \mathrm{~mL}$ of extract at around $475 \mathrm{~nm}$. A weak adsorbance peak was observed at $0.29 \mathrm{AU}$ in $5 \mathrm{~mL}$ of extract and mild reduction of adsorption of silver ions at $0.48 \mathrm{AU}$ with $10 \mathrm{~mL}$ of extract. The $15 \mathrm{~mL}$ of extract was checked for bioreduction at time intervals over 3 to 18 hours. The evolution of UV-vis spectrum of synthesized silver nanoparticles have an increasingly sharp adsorbance peak identified at around $475 \mathrm{~nm}$ in the adsorption spectra of silver nanoparticles. Adsorption peak was not clear in the $5 \mathrm{~mL}$ and $10 \mathrm{~mL}$ extracts, but a sharp peak was observed at the higher dosage level $15 \mathrm{~mL}$ and peak resolution was also very clear. The bioreduction of silver ions was increased at the end of 10 hours of reaction time, as illustrated in Figure 2. Reductive biomolecules for reduction of gold ions were responsible for the formation of the few nanoparticles, as the maximum adsorbance is much lower than that in $10 \mathrm{~mL}$ and $15 \mathrm{~mL}$ extracts.

A

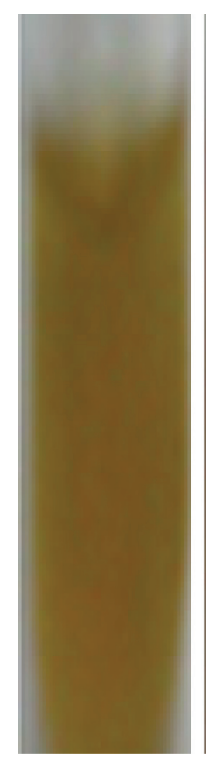

B

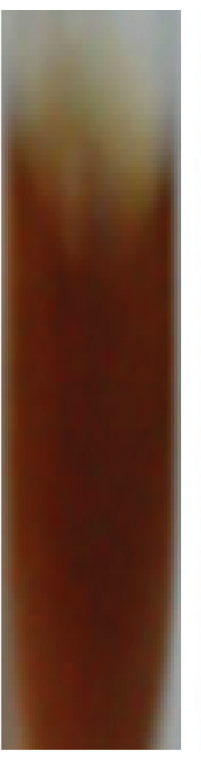

Figure I Optical photograph of the colloidal solution of silver nanoparticles reduced by Memecylon edule leaf extract at $(5,10$ and $15 \mathrm{~mL})$. Color change occurred due to surface plasmon resonance (A) M. edule leaf extract (B) $5 \mathrm{ml}$ of extract with $\mathrm{Ag}^{+}$solution (C) $10 \mathrm{~mL}$ of extract with $\mathrm{Ag}^{+}$solution (D) $15 \mathrm{~mL}$ of extract with $\mathrm{Ag}^{+}$ solution after the process of $\mathrm{Ag}^{+}$to $\mathrm{Ag}$ nanoparticles.

Abbreviations: AgNPs, silver nannoparticles; SPR, surface plasmon resonance. 
A

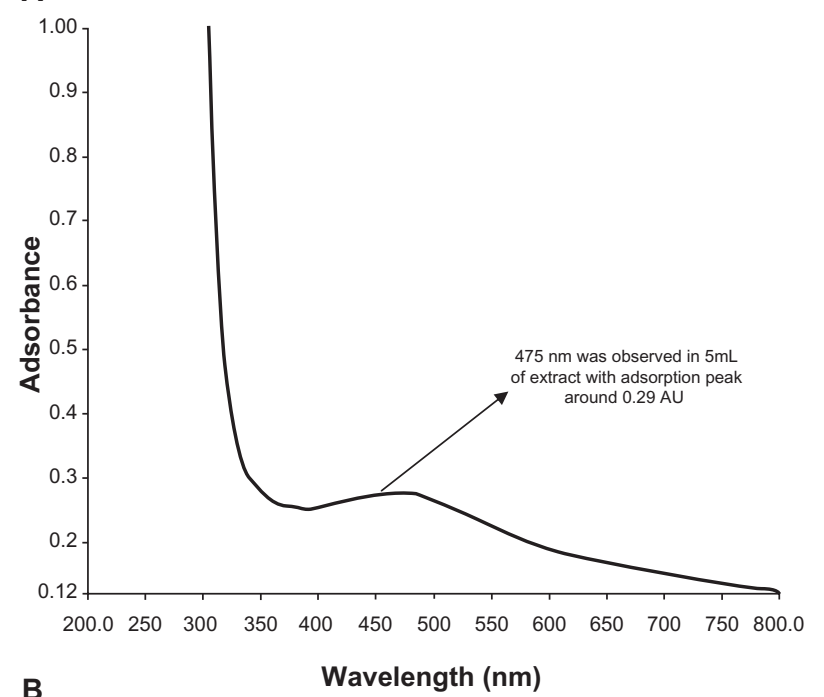

B

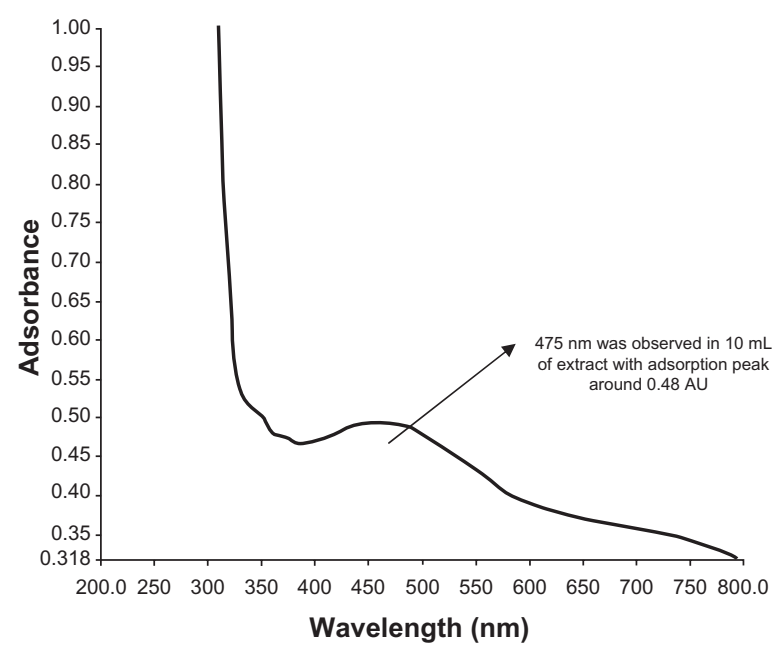

C

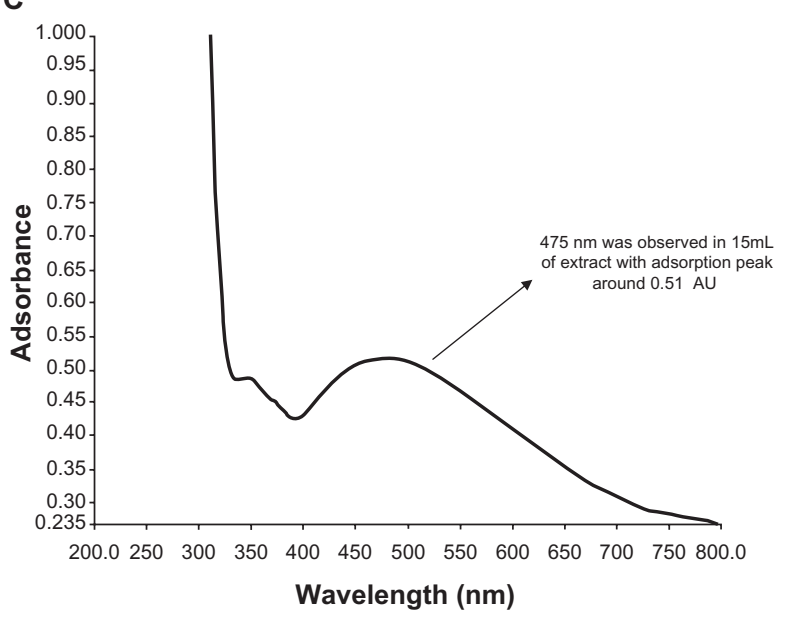

D

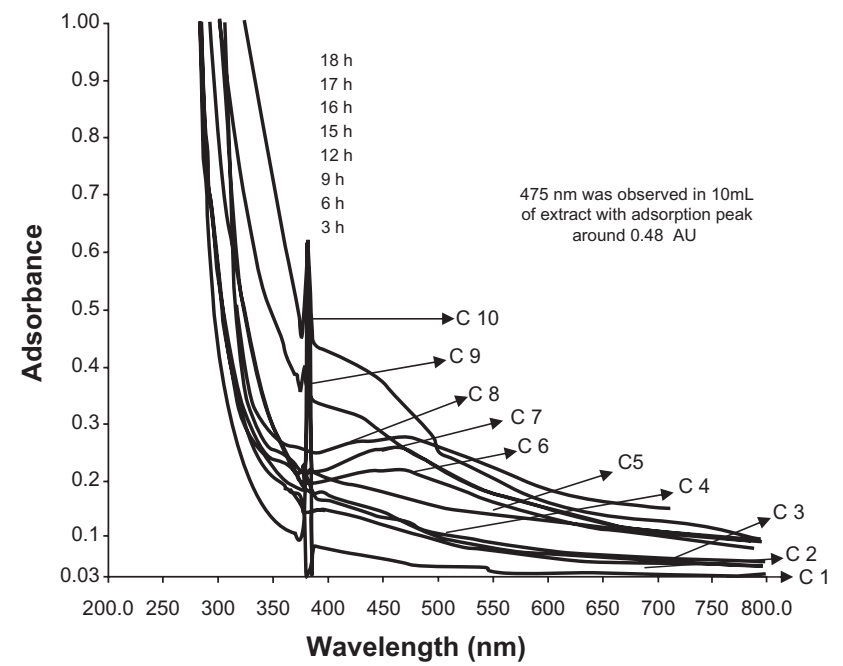

Figure $2 \mathrm{UV}$-vis adsorption spectra of silver nanoparticles after bioreduction kinetics of the reaction of $M$. edule leaf extract with aqueous silver ions at $5 \mathrm{~mL}(\mathbf{A})$, $10 \mathrm{~mL}$ (B), $15 \mathrm{~mL}$ (C) in the concentration range of $200-800 \mathrm{~nm}$ with different time intervals. A) $5 \mathrm{~mL}$ of silver and leaf aqueous solution (B) $10 \mathrm{~mL}$ of silver with leaf aqueous solution and (C) $15 \mathrm{~mL}$ of silver with leaf aqueous solution. D) Curves I-10 correspond to 3, 6, 9, I2, 15, 16, 17, 18, 21,24 hours of reaction time, respectively, in $15 \mathrm{~mL}$ of leaf extract with silver aqueous solution.

Abbreviation: $\mathrm{C}$, curves.

Previous reports from Huang et al on C. camphora show that silver nanoparticles may grow in a process involving rapid bioreduction and that they strongly influence the SPR in the water extract. ${ }^{22}$ This is accordance with the results obtained from bioreduction of silver nanoparticles using Spirulina Platensis, which showed that a SPR silver band occurred at $400-480 \mathrm{~nm}^{21,32}$

Aqueous extracts of $M$. edule possess remarkable antioxidant activity and they should be considered important neutraceuticals. We are studying other biological activities of gold and silver nanoparticles of M. edule in vitro and in vivo properties, which we will communicate shortly. A phytochemical study of this genus (Memecylon) showed the presence of triterpenes, flavonoids, and tannins. The first systematic phytochemical survey was conducted in Malaysia by Said et al, of Melastomataceae and some other families for alkaloids, triterpenoids, steroid compounds, saponins, essential oils, glycosides, and hydrogen cyanide. ${ }^{9}$ They identified saponin as a major compound in the leaves of Memecylon sp and, further, that this compound is involved in taste properties (bitterness), flavor, and pigmentation. ${ }^{8,33}$ Aqueous extracts of Teucrium polium, Angelica sinensis, Lycium barbarum, and Lycium cocos have strong antioxidant activity. Free radicals are known to be the main cause of aging, coronary heart disease, stroke, ${ }^{34}$ diabetes mellitus, rheumatism, and cancer. ${ }^{35,36}$ The antioxidant activity 
of nanoparticulate saponin is potentially therapeutic for a variety of diseases including cancer and aging, and nanoparticulate saponin is also used to treat hypersensitivity. ${ }^{37}$ Our preliminary work here has confirmed the nanosaponin present in $M$. edule could be a good remedial plant source for many diseases.

Figure 3 shows representative SEM images recorded at different magnifications from drop-coated films of the silver nanoparticles synthesized by treating $\mathrm{AgNO}_{3}$ solution with $M$. edule leaf broth. The resulting silver nanoparticles were predominantly square and of uniform size. Higher magnification showed the average diameter of these square nanoparticles to be about 50 to $90 \mathrm{~nm}$. SEM images of biologically synthesized typical silver nano irregular particles (the shape of the nanoparticles were not clearly predicted) were obtained from $15 \mathrm{~mL}$ of leaf extract. The resulting nanoparticles showed that a small percentage of spherical particles were in the size range 10-45 $\mathrm{nm}$. SEM images of the nanotriangles in the same suspension are depicted in Figure 3. Silver ions were not well separated from each other in the nanotriangles and dimensions in the size range 45-60 $\mathrm{nm}$ are capped with smaller particles due to the presence of small crystal and hexagonal particles on the triangular surface $10-25 \mathrm{~nm}$ in diameter.

The SEM analysis of silver nanoparticles of $M$. edule support the results of Govindaraju et al in S. platensis. ${ }^{38,39}$ In addition, rapid biosynthesis of silver nanoparticles in different shapes (twinning, mixed structures, dislocations) was observed and sizes of nanoparticles were increased by high concentrations of leaf extract of $M$. edule. It is interesting that the size of the triangular silver nanoparticles shown in Figure 3 increased to about $60 \mathrm{~nm}$ in size as the dosage of M. edule leaf extract increased to $15 \mathrm{~mL}$. The size of silver nanoparticles obtained in the present investigation is supported by previous studies. ${ }^{22}$ According to nanoparticle size of M. edule, results obtained was comparable with silver nanoparticles synthesized by using $C$. camphora size ranging mostly from 55 to $80 \mathrm{~nm},{ }^{22}$ and 31 to 40 on C. zeylanicum. ${ }^{40,41}$

Figure 3 shows the selected-area electron diffraction (SAED) pattern recorded from this triangular- and irregularshaped single crystalline could be indexed based on the structure of silver nanoparticles. The square-shaped nature of the diffraction crystals are a clear indication.

To summarize these results, the size of the silver nanoparticles obtained from $M$. edule can be increased when adding a dosage of $15 \mathrm{~mL}$ to silver solution. As a result, researches in the field of nanoparticle synthesis described that these silver nanoparticles obtained from plant extracts can be used for medical purposes. The EDAX technique is used to further identify the silver nanoparticles of M. edule.

Together with TEM images it is interesting that the EDAX profile of silver nanoparticles showed strong silver signals for silver atoms as shown in Figure 3. The EDAX pattern thus clearly shows that the silver nanoparticles are crystalline in nature by the reduction of silver ions by using $M$. edule leaf broth. The EDAX analysis obtained in the present study (shown in Figure 3F) confirmed that the presence of silver nanoparticles of $M$. edule and mostly showed strong signal energy peaks for silver atoms in the range $2-4 \mathrm{keV}$. In an earlier study, Gardea-Torresdey et al obtained formation of individual spherical-shaped silver nanoparticles in the range $2.5-4 \mathrm{keV}$ by using Alfalfa $^{23}$

The size distribution and characterization of silver nanoparticles could be further verified by FTIR in M. edule to synthesis nanoparticles. Figure 4 shows the adsorption band at about 1028.14, 1161.79, 1261.90, 1384.80, 1495.40, $1631.54,1730.82 \mathrm{~cm}^{-1}$. FTIR measurements were carried out to identify the silver nanoparticles in the M. edule leaf broth. Among them, observed adsorbance spectra band at 1028.14, 1384.80 , and $1631.54 \mathrm{~cm}^{-1}$ are more characteristic and mainly responsible for the bioreduction of silver ions.

Among them strong silver adsorbance band at 1384.80 was associated with the stretch vibration of functional groups such as $-\mathrm{C}-\mathrm{O}-\mathrm{C}-,-\mathrm{C}-\mathrm{O}-,-\mathrm{C}=\mathrm{C}, \mathrm{C}=\mathrm{O}$. FTIR spectrum of the $M$. edule showed peaks indicating the presence of saponin (an important water soluble component) and this overall observation confirms the presence of saponin.

This present result obtained from $M$. edule agrees with those reported previously for C. camphora, S. platensis, ${ }^{21,37,17}$ Among them, the adsorbed peaks of silver nanoparticles in $M$. edule at $1631 \mathrm{~cm}^{-1}$ were associated with the stretch vibration of $-\mathrm{C}=\mathrm{C}$, and the adsorbance peak as located at around $1028 \mathrm{~cm}^{-1}$ can be assigned as the $\mathrm{C}-\mathrm{N}$ stretching vibrations of amine. Similarly bioreduction of $\mathrm{AgNO}_{3}$ by Azadirachta indica led to the formation of silver nanoparticles in the adsorption peak range observed at $1608 \mathrm{~cm}^{-1}$, $1384 \mathrm{~cm}^{-1}$, and $1076 \mathrm{~cm}^{-1}$. Moreover, the above observed peaks of $M$. edule are more characteristic of terpenoid and flavonoid group components in having the ability to adsorb on the surface of silver nanoparticles. It plays a major role in the reduction of nanoparticles by interaction through carbonyl groups and in the oxidation of aldehyde groups in carboxylic acids. ${ }^{42}$ Our observation lends support to a previous study in which formation of spherical silver and triangular gold nanoparticles was reported by using various plant extracts. Further, the FTIR patterns of $M$. edule prove to be 

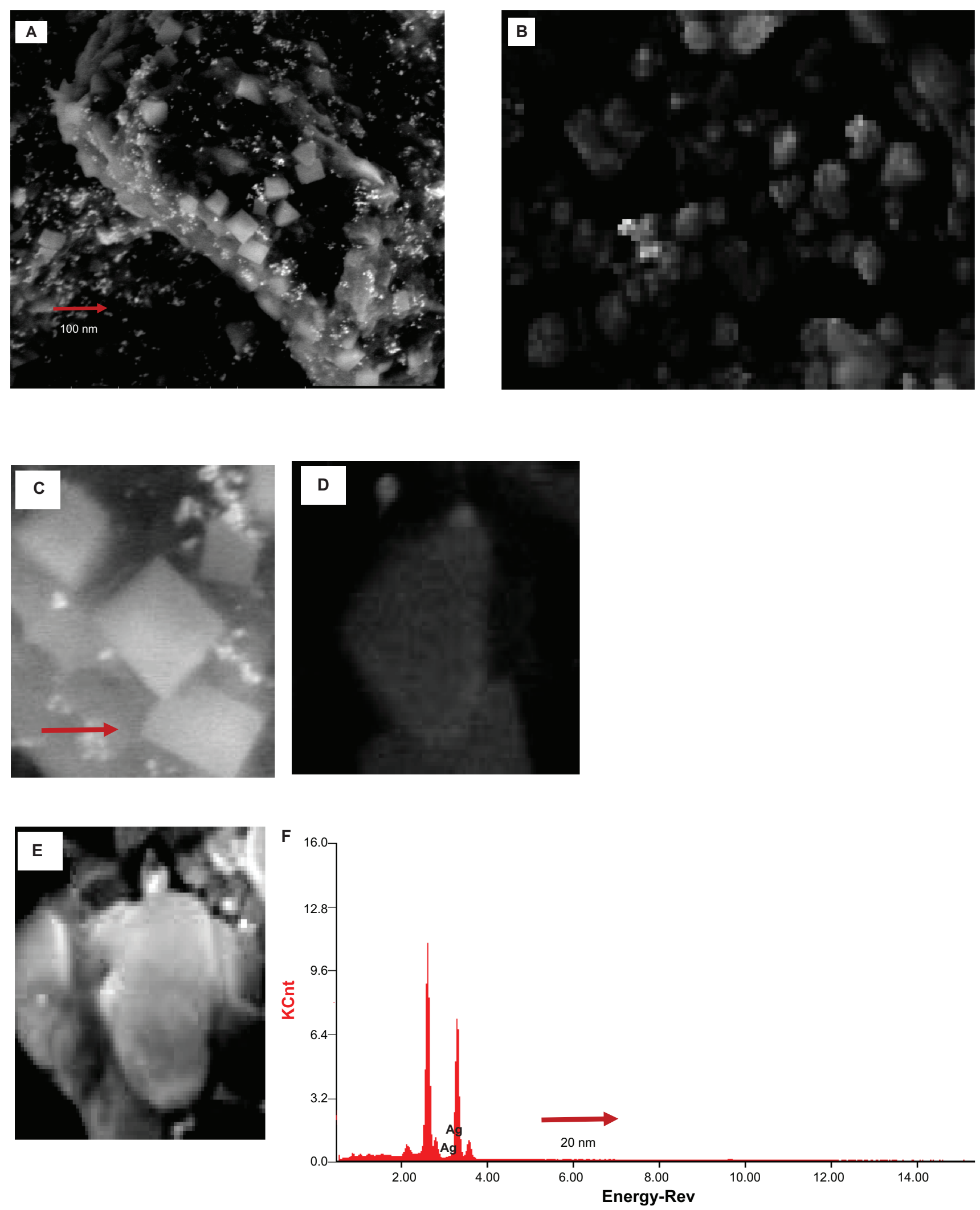

Figure 3 SEM images of the silver nanoparticles after bioreduction of $\mathrm{AgNO}_{3}$ with Memecylon edule leaf extract. $100 \mathrm{~nm}(\mathbf{A}), 50 \mathrm{~nm}$ (B), SEM images of silver nanoparticles with corresponding (SAED) selected area electron diffraction patterns showing square-shaped crystals (C), irregular-shaped particle (D), and triangular-shaped particle in $20 \mathrm{~nm}$ (E). EDAX profile of silver nanoparticles resulting from the experiment by using the $15 \mathrm{~mL}$ of $M$. edule extract. (F).

Abbreviations: SAED, selected area electron diffraction; EDAX, energy dispersive X-ray. 


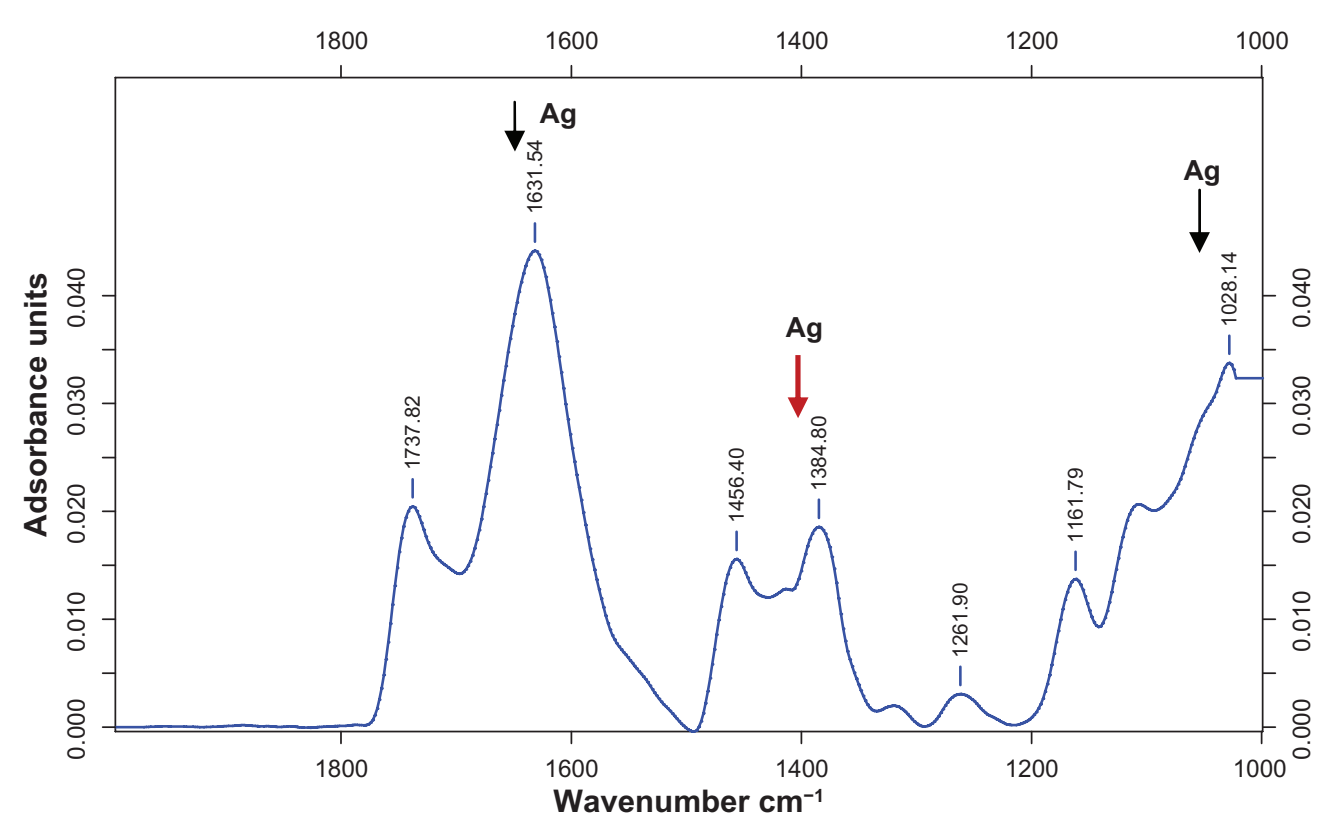

Figure 4 Typical FTIR adsorption spectra of silver nanoparticles synthesized by M. edule leaf extract after bioreduction of silver ions. Abbreviation: FTIR, Fourier transform infra-red spectroscopy.

powerful evidence in favor of the UV-vis spectra and SEM images for the presence of silver nanoparticles. Although, as mentioned earlier, it has also been found to be responsible for the reduction of silver ions when using Gliricidia sepium for the synthesis of silver nanoparticles. ${ }^{29}$

\section{Green synthesis of gold nanoparticles}

The reduction of chloroaurate ions was much more rapid than that of silver ions. On addition of $M$. edule biomass to $10^{-3} \mathrm{M}$ aqueous $\mathrm{HAuCl}_{4}$, the color of the shaken solution changed from pale yellow to pink ruby red color, indicating formation of gold nanoparticles almost at the beginning of the reaction. These color changes arose due to excitation of SPR with the gold nanoparticles.

Figure 5 shows the UV-vis spectra recorded from the aqueous $\mathrm{HAuCl}_{4}$ with $M$. edule reaction medium, as a function of time of reaction. The SPR band occurred at $555 \mathrm{~nm}$ within 1 hour of reaction time. The strong gold resonance peak occurred in $530 \mathrm{~nm}$ and increased in intensity as a function of time. The color did not change further after 18 hours of reaction time.

The bioreduction rate of the gold ions occurs quickly; more than $90 \%$ of the reduction of gold ions is complete in 18 to 21 hours after addition of the $M$. edule leaf broth to the gold solution. In earlier studies on the synthesis of gold nanoparticles using bacteria and fungi, the time required for complete reduction ranged from 24 to 120 hours. It is generally accepted that UV-vis spectroscopy measurements could be used to check the reduction of the silver and gold nanoparticles. In earlier studies by Shankar et al and Dubay et al, it was reported that the gold nanoparticles obtained (after 13 hours) after the addition of tamarind leaf broth to the $\mathrm{AgNo}_{3}$, a visible color change was noticed, from colorless to yellowish-brown to ruby red, due to the excitation of SPR in gold nanoparticles. ${ }^{42,43}$ Figure 6 displays the SEM images of typical nanoparticles, produced by $15 \mathrm{~mL}$ of $M$. edule leaf extract with gold ions recorded at different magnifications. The resulting nanoparticles were polydisperse. Triangular or circular gold nanoparticles with an irregular edge can occur at 500, 200, 100, and $50 \mathrm{~nm}$. Large uniform square-shaped particles produced by fast reduction of gold ions with $15 \mathrm{~mL}$ of $M$. edule extract in $200 \mathrm{~nm}$ are shown in Figure 6. An individual gold nanohexagonal tilting against the carbon-coated copper grid with an average edge length was measured to be about $85 \mathrm{~nm}$. All the nanohexagonal shapes under low resolution were thin, flat, and sharp edged. According to size, distribution of the gold nanoparticles ranged from 20 to $35 \mathrm{~nm}$ with high frequency and possessed a square-shaped, plate-like morphology.

The sintering of some gold nanoparticles formed in M. edule were predominantly nanotetrahedral. Under careful observation, it was noted that the gold nanoparticles were surrounded by procircular shapes on the surface of the tetrahedral region. However, gold nanoparticles synthesized 


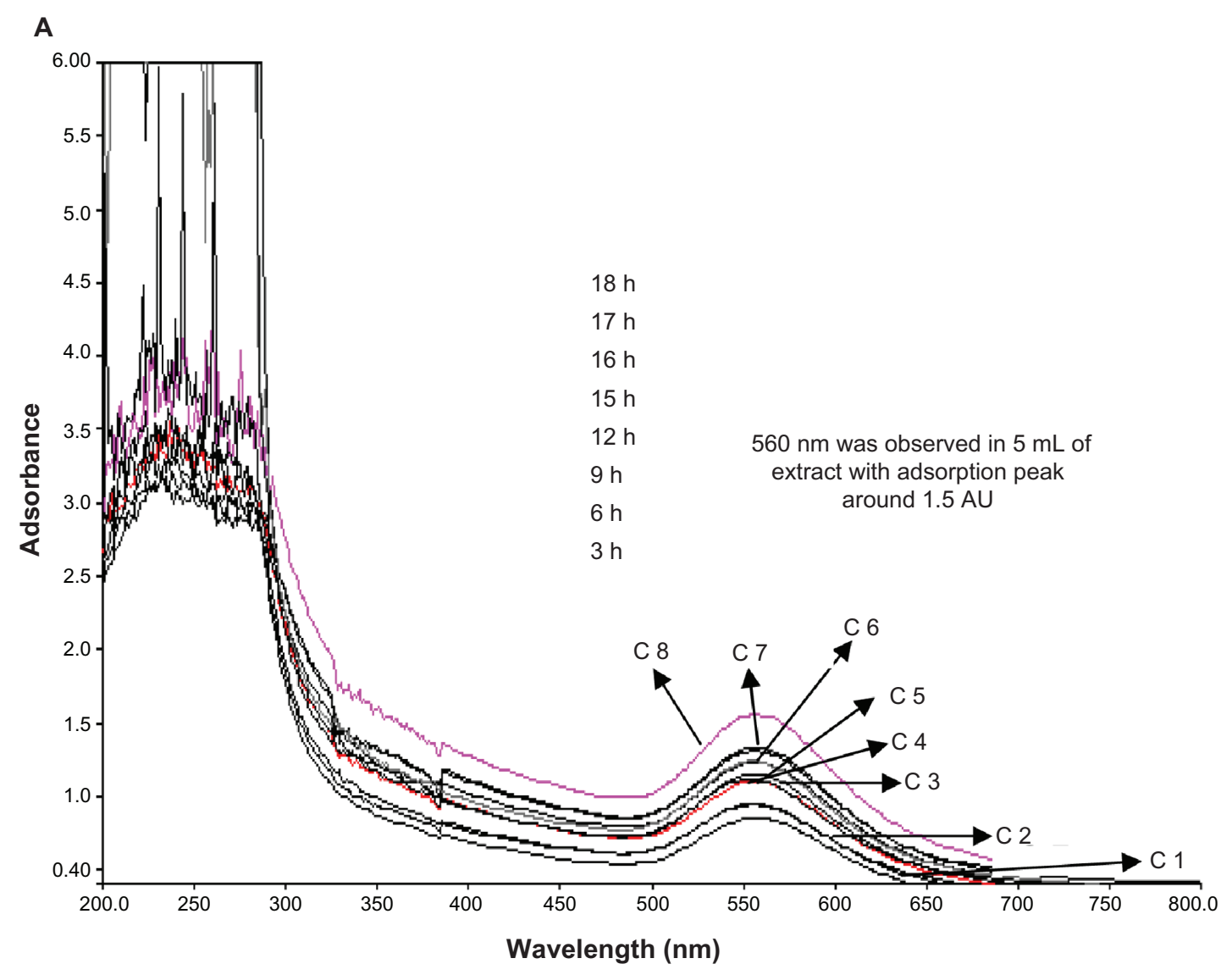

B

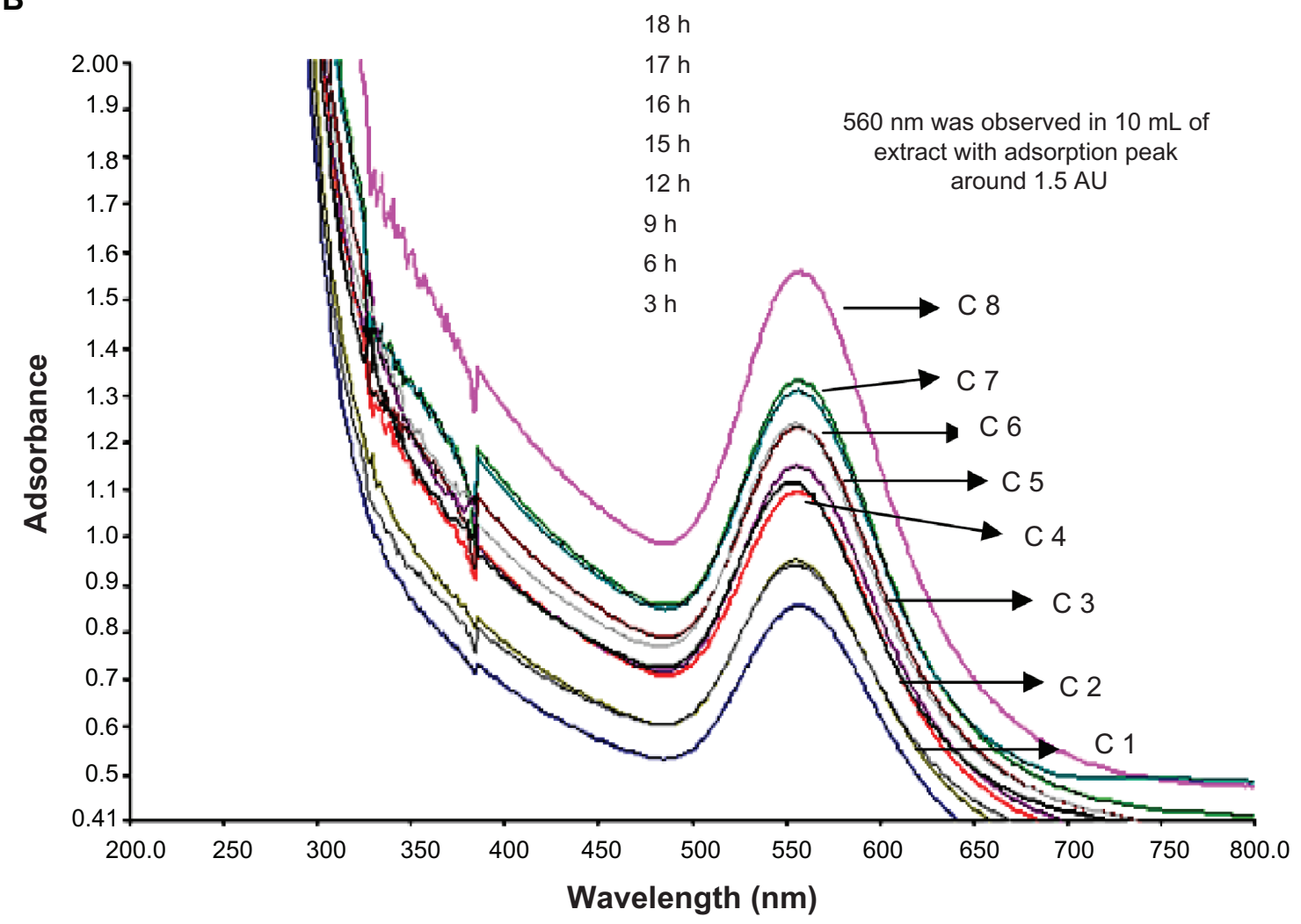

Figure 5 (Continued) 


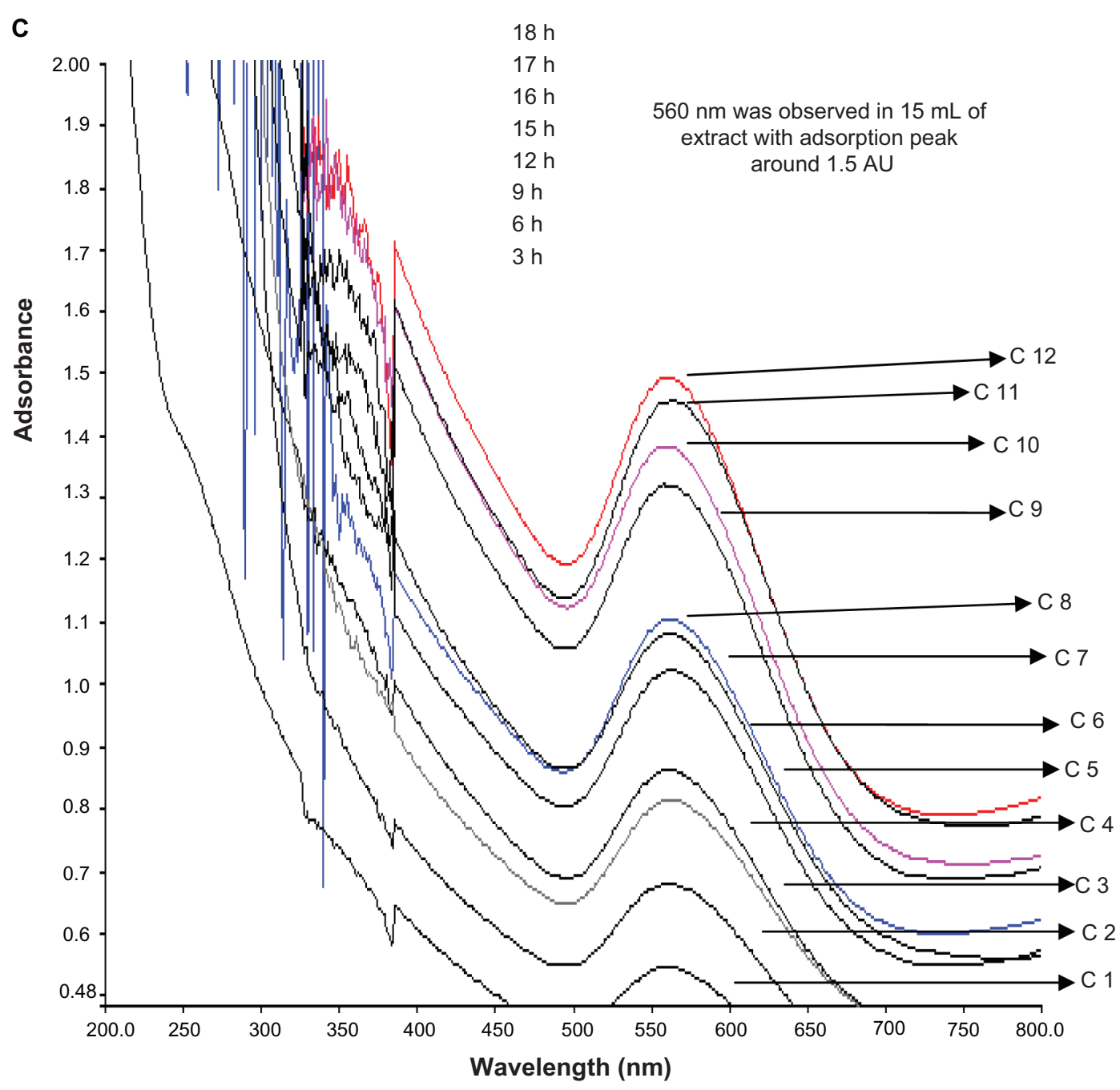

Figure 5 UV-vis bioreduction kinetics of the reaction of $M$. edule leaf extract with aqueous chloroaurate ions at 5 , I0, and I5 $\mathrm{mL}$ concentration in the range of $200-800 \mathrm{~nm}$ with different time intervels. $5 \mathrm{~mL}$ of gold and leaf aqueous solution $(\mathbf{A}), 10 \mathrm{~mL}$ of gold and leaf aqueous solution (B), and I5 mL of gold and leaf aqueous solution (C). Curves I-12 correspond to $3,6,9,12,15,16,17,18,21,24,27$ hours of reaction time, respectively.

Abbreviation: $\mathrm{C}$, curves.

using M. edule appear to have sharp angled edges on the surface of the particles. It is generally accepted that the shape of gold nanoparticles affects their optical, electronic, and catalytic properties.

From Rubio et al, ${ }^{44}$ an experimental example from the solution growth of gold nanoparticles studied by scanning electron microscopy is presented in Figure 6, where icosohedral multiple twin-shaped gold nanoparticles were observed at a particle size of about 50-80 $\mathrm{nm}$ in the leaf broth of M. edule. Large numbers of nano spherical particles were observed, ranging in size from 20 to $50 \mathrm{~nm}$, with an average particle size of $25.2 \mathrm{~nm}$. The size distribution of the gold nanoparticles was narrow, mostly ranging from 55 to $80 \mathrm{~nm}$.

Rejinolda et al reported that saponin-loaded nanoparticles were observed in the SEM with sizes of about 65-72 nm which are therapeutic for cancer. In the current study, experimental evidence was obtained using SEM analysis, which clearly shows the strong gold nanoparticles in the above size range in the M. edule leaf extract. ${ }^{38}$

Gold nanospindle-shaped particles were observed at higher adsorbance. As discussed above, the rate silver nanoparticle formation is relatively slow when compared with that of gold nanoparticles. Gold nanoparticles were formed on very small pieces of leaf of M. edule by a process involving rapid reduction. A low magnification TEM image recorded from the biologically synthesized gold nanoparticles at the end of the reaction with M. edule leaf extract showed that the gold nanoparticles were predominantly triangular, circular, and hexagonal in morphology. A large quantity of circular gold nanoparticles with thin, smooth ends on the exterior of the nanoparticles was seen in the TEM micrographs. 

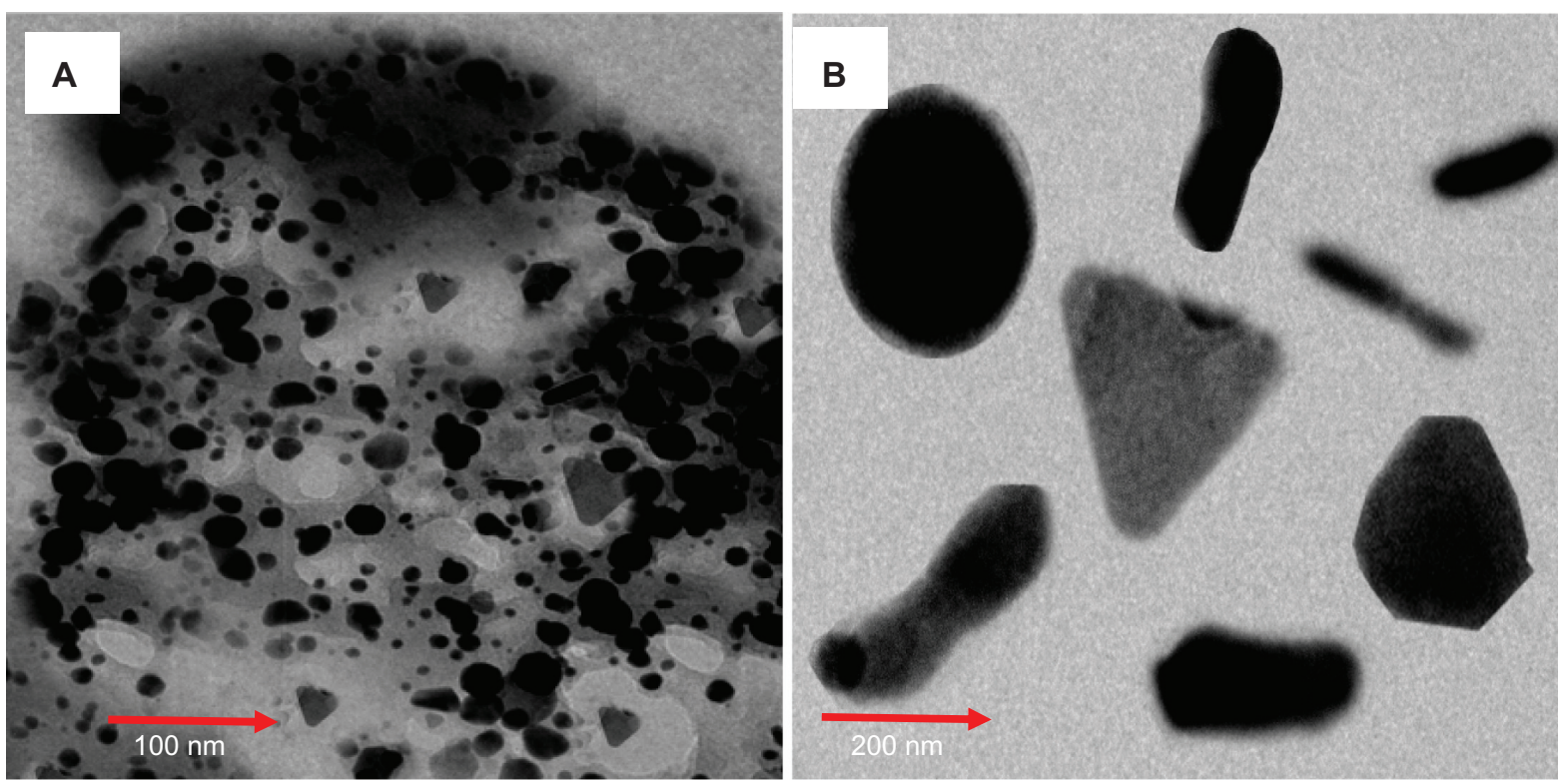

C

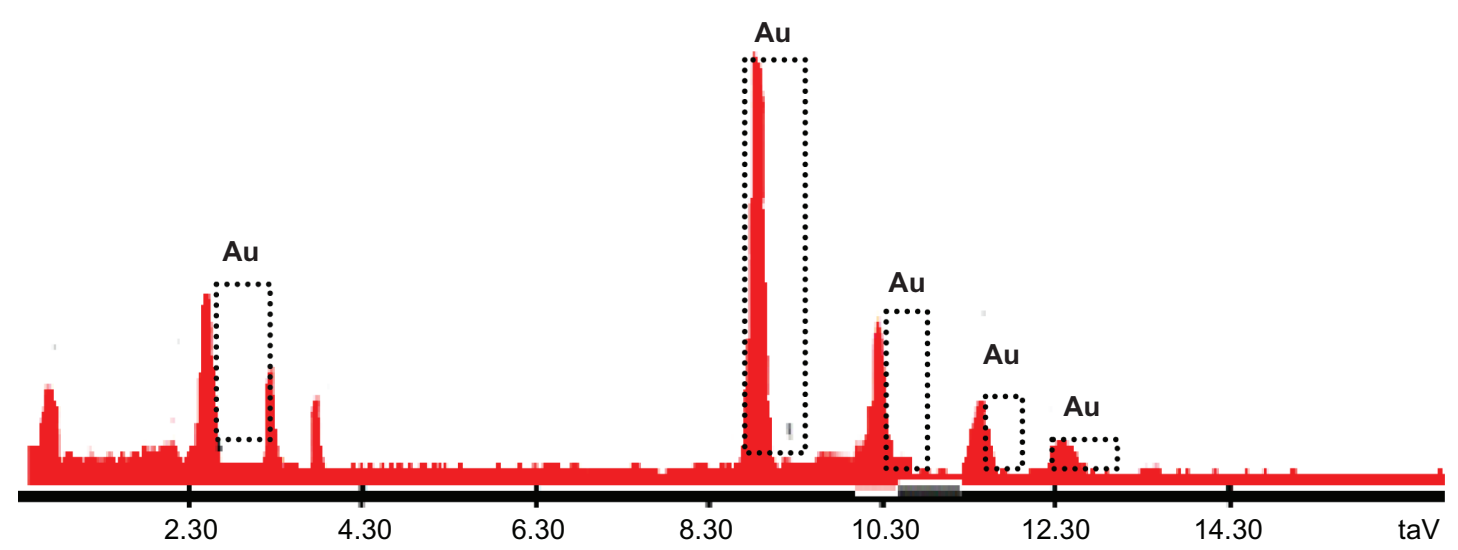

Figure 6 TEM images and EDAX spectrum of gold nanoparticles. Representative TEM image obtained by the reduction of aqueous AuCl-ions using $\mathrm{Memecylon}_{4}$ edule leaf extract. Scale bars: $200 \mathrm{~nm}$ (A); high magnification TEM micrograph of a single gold nanotriangle, circular, spindle, hexagon (B); energy dispersive X-ray spectrum of gold nanoparticles resulting from the experiment using $15 \mathrm{~mL}$ of $M$. edule leaf extract (C).

The biologically obtained nanotriangles consisted of a mixture of triangles and truncated triangles. The overall morphology of the gold nanoparticles of the M. edule sample produced by bioreduction of gold ions with $15 \mathrm{~mL}$ of extract dosage is shown in Figure 7. Most of the gold nanoparticles ranged in size from 10 to $45 \mathrm{~nm}$. At higher magnification, the average diameter of these nanoparticles was found to be approximately $24.3 \mathrm{~nm}$.

Similar results have been reported for gold nanoparticles, although Shankar et al reported a nanoparticle size range of 50-100 nm and many of the observed structures of nanoparticles were spherical when $A$. indica leaf extract was used as a biomaterial. ${ }^{42}$ Most of the nanoparticles formed tended to be triangular or spherical in the observed hydrosol results at around 570 and $1000 \mathrm{~nm}$ adsorbance. These above structures were similar to that of gold nanoparticles produced from the leaf extract of C. camphora. ${ }^{21}$

The spherical gold nanoparticles were further confirmed by using EDAX spectrometry, which confirmed the presence of gold with no other contaminants. The optical adsorption peak was observed at approximately $2.30 \mathrm{keV}$, which is typical for the adsorption of gold nanocrystallites due to SPR.

The current profile of EDAX of gold nanoparticles of M. edule showed strong gold atom signals around 2.30, 9, $10.30,11.30$, and $12.30 \mathrm{keV}$. The EDAX of gold nanoparticles showed strong signals for gold atoms. All the gold nanoparticles under EDAX observation of $M$. edule show similar results to other plants including coriander and $C$. camphora. ${ }^{20-22}$ 

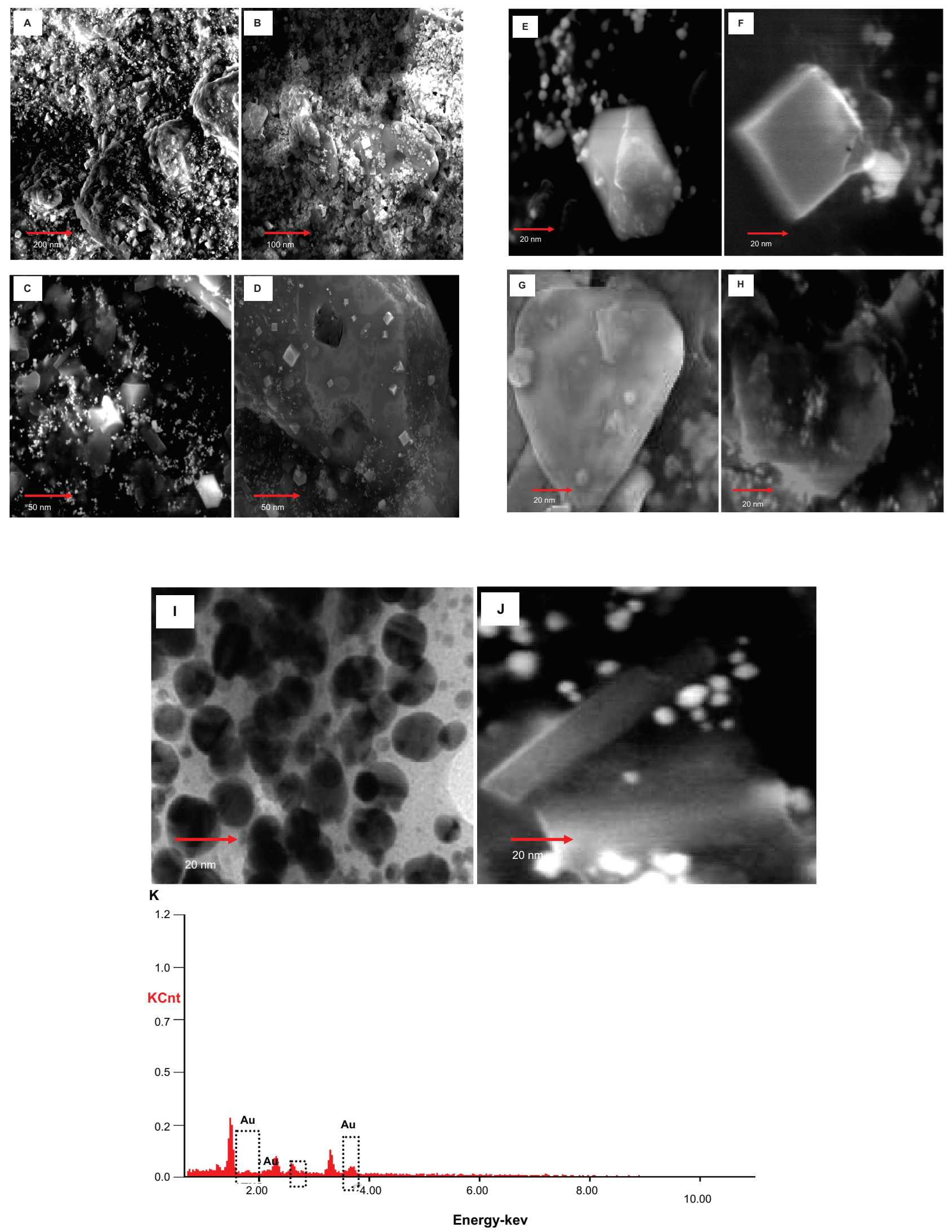

Figure 7 SEM micrographs of the different kinds of gold nanoparticles observed from the reaction of $\mathrm{Au}^{3+}$ cations with Memecylon edule leaf extract: scale bar $500 \mathrm{~nm}$ (A), $200 \mathrm{~nm}$ (B), $100 \mathrm{~nm}$ (C), $50 \mathrm{~nm}$ (D). SEM images of gold nanoparticles with corresponding selected area electron diffraction (SAED) patterns of the nanocrystalline M. edule samples at $20 \mathrm{~nm}$. Hexagonal $(\mathbf{E})$, square $(\mathbf{F})$, tetrahedral $(\mathbf{G})$, icosahedral multiple twinned $(\mathbf{H})$, circular $(\mathbf{I})$ spindle $(\mathbf{J})$, energy dispersive X-ray spectrum equipped with SEM of gold nanoparticles resulting from the experiment using $15 \mathrm{~mL}$ of $M$. edule leaf extract $(\mathbf{K})$. 
Most of the previous research has demonstrated that the reduction of chloroaurate ions was much faster than that of silver ions and arrangement of atoms inside the gold nanoparticles was disordered in the size range $25-85 \mathrm{~nm}$. FTIR clearly showed that more functional groups could be available for a large number of $\mathrm{Au}(\mathrm{III})$ complexes with the plant extract simultaneously. The lower wavenumbers, followed by the disappearance of the gold resonance, may be due to its binding with the gold nanoparticle surface..$^{40,44}$

Figure 8 shows the FTIR measurements carried out to identify the functional groups involved in the bioreduction of gold nanoparticles in the M. edule leaf broth. Representative FTIR spectra of the obtained nanoparticles are also shown in this figure. The spectrum reduced gold with the adsorption peak located at about $1618.93,1452.80,1378.82$, $1384.80,1319.69,1166.01,1112.15,1056.43 \mathrm{~cm}^{-1}$, in the region of 1000 to $1800 \mathrm{~cm}^{-1}$. These bands are characteristic of carbonyl stretching vibration in ketones, aldehydes, and carboxylic acids. Three adsorption peaks located at around $1618 \mathrm{~cm}^{-1}$ ( $\mathrm{C}=\mathrm{C}$ or aromatic groups), $1452 \mathrm{~cm}^{-1}$ (geminal methyls), and $1056 \mathrm{~cm}^{-1}$ (aromatic $\mathrm{C}-\mathrm{C}$ ) were observed for gold nanoparticles. In addition, there were some strong adsorption spectra in the region $1600-1700 \mathrm{~cm}^{-1}$.

In earlier studies, Govindaraju stated that FTIR spectra of the synthesized gold nanoparticles of S. platensis showed gold ion peaks around 1653, 1541, and $1242 \mathrm{~cm}^{-1} .{ }^{37}$ For gold nanoparticles, the adsorption at about 1725, 1615, 1401, 1228,1140 , and $1076 \mathrm{~cm}^{-1}$ has been found to be responsible for the reduction of gold ions when using A. indica. ${ }^{41}$ Present FTIR observation of $M$. edule lends support to a previous study on the reduction of gold nanoparticles, using C. camphora, in the gold ion peak region at 1038,1387 , and $3418 \mathrm{~cm}^{-1}$, corresponding to $\mathrm{C}-\mathrm{N}$ stretching vibrations of amine, $\mathrm{C}-\mathrm{N}$ stretching of aromatic amine group, and $\mathrm{NH}$ stretching of amide (II) band..$^{22,43,44}$ The result obtained in the present study is supported by previous reports. ${ }^{45,46}$ FTIR spectrum of tamarind leaf broth-reduced gold nanoparticles shows the adsorption bands at $1744 \mathrm{~cm}^{-1}$ and $1616 \mathrm{~cm}^{-1}{ }^{40}$ The same observed gold peaks of M. edule were more characteristic of terpenoids. ${ }^{45-49}$

\section{Conclusion}

We have demonstrated the M. edule could be an excellent bioreductant and easily available plant source for green synthesis of silver and gold nanoparticles. The M. edule aqueous leaf extract appears to be environmentally friendly and therefore this protocol could be used for the rapid production of silver nanoparticles. The size of silver and gold particles could be easily adjusted by using different amounts of leaf extract.

The successful synthesis of gold and silver nanoparticles by reducing silver and gold ions using an aqueous extract of

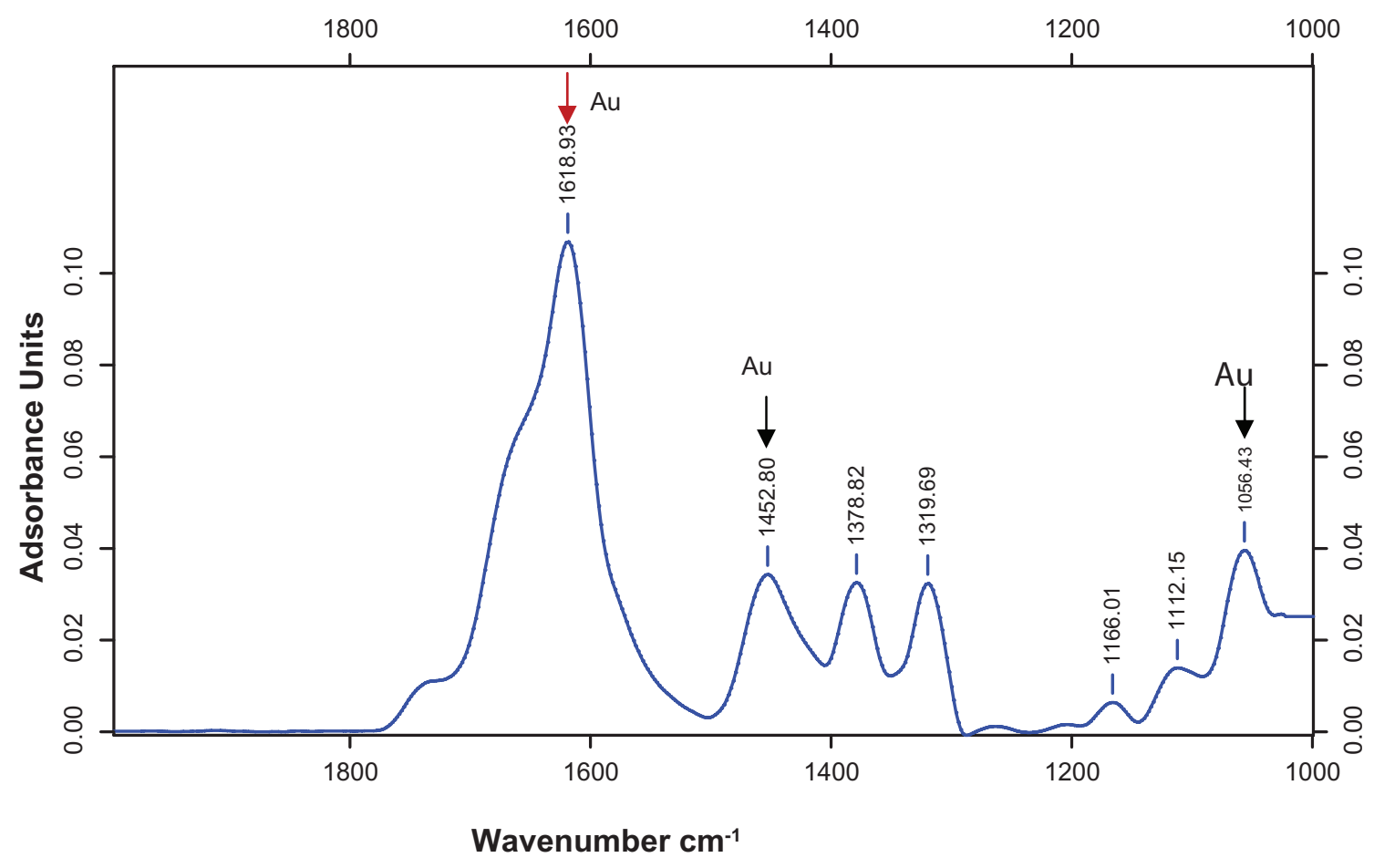

Figure 8 Typical FTIR adsorption spectra of the nanoparticles synthesized by bioreduction of $\mathrm{AuCl}_{4}$ ions by $\mathrm{M}$. edule leaf broth. 
M. edule leaves, showed that the reduction rate of silver ions is much faster than for gold. Water soluble compounds present in the M. edule, like saponins, were mostly responsible for the reduction of silver and gold ions to nanosized silver and gold particles. The reduction rate of $\mathrm{HAuCl}_{4}$ also varied and color intensity was changed due to the formation of gold nanoparticles. The reaction of the ingredients present in the plant leaf extract analyzed by UV-vis spectroscopy revealed that silver nanoparticles in the solution may be correlated with the UV-vis spectra. This change of color indicates the formation of silver nanoparticles.

\section{Acknowledgments}

The authors acknowledge financial support from the SRM University, Kattankulathur. The authors also thank: Dr D Narasiman, Centre for Floristic Research, Department of Botany, Madras Christian College, Chennai, Tamilnadu, India, for the identification of the plant sample; Gopalakrishnan, Department of Nanotechnology, SRM University, Kattankulathur; Dr KS Lakshmi, SRM College of Pharmacy, SRM University, Kattankulathur, for providing the laboratory facilities for UV-visible spectroscopy and FTIR analysis; K Manikandan, SRM College of Pharmacy, SRM University, Kattankulathur, for technical support. Ms Elavazhagan acknowledges the fellowship from SRM University, Kattankulathur, and is also thankful to the Department of Biotechnology, School of Bioengineering, SRM University, Kattankulathur, for financial support and providing the necessary infrastructure to carry out this work.

\section{Disclosure}

The authors declare no conflicts of interest in this work.

\section{References}

1. Clausing G, Renner SS. Molecular phylogenetics of Melastomataceae and Memecylaceae: implications for character evolution. Am J Bot. 2001;88:486-498.

2. Daniels RJ, Ramachandran VS, Vencatesan J, Ramakantha V, Puyravaud JP. Dispelling the myth of tropical dry evergreen forests of India. Current Science. 2007;92:586-588.

3. Sussane S. Renner. Bayesian analysis of combined chloroplast loci, using multiple calibrations, supports the recent arrival of melastomataceaein Africa and Madagascar. Am J Bot. 2004;91:1427-1435.

4. Fritsch PW, Almeda F, Renner SS, Martins AB, Cruz BC. Phylogeny and circumscription of the near-endemic Brazilian tribe Microlicieae (Melastomataceae). Am J Bot. 2004;91:1105-1114.

5. Bumrungsri S, Sripao-raya E, Leelatiwong C. A quantitative analysis of plant community structure in an abandoned rubber plantations on KhoHong Hill, southern Thailand.

6. Songklanakharind Journal of Science and Technology. 2006;28: 479-491.

7. Nadkarni KM. Nadkarni's Indian Materia medica. Popular Prakashan. 1996;2:787-788.
8. Kongkachuichay P, Shitangkoon A, Chinwongamorn N. Thermodynamics of adsorption of laccaic acid on silk. Dyes Pigm. 2002;53: 179-185.

9. Said IM, Din LB, Samsudin MW, et al. Phytochemical Survey of Sayap-Kinabalu Park, Sabah. A Scientific Journey Through Borneo Sayap-Kinabalu Park Sabah. Kuala Lumpur, Malaysia: Pelanduk Publications; 1995:137-144.

10. Khare CP. Indian Medicinal Plants an Illustrated Dictionary. New Delhi, India: Springer Verlag; 2007.

11. Braditchote S, Wongkrajang Y, Nahrstedt A. Anti-inflammatory, analgesic and wound healing activities of the leaves of Memecylon edule Roxb. J Ethnopharmacol. 2009;121:278-281.

12. Mandal D, Bolander ME, Mukhopadhyay D, Sarkar G, Mukherjee P. The use of microorganisms for the formation of metal nanoparticles and their application. Appl Microbiol Biotechnology. 2006;69: 485-492.

13. Armendariz V, Herrera I, Peralta-videa JR, et al. Size controlled gold nanoparticle formation by Avena sativa biomass use of plants in nanobiotechnology. J Nanopart Res. 2004;6:377-382.

14. Andreeva D. Low temperature water gas shift over gold catalysts. Gold Bull. 2002;35:82-88.

15. Mukherjee P, Bhattacharya R, Bone N, et al. Potential therapeutic application of gold nanoparticles in B-chronic lymphocytic leukemia (BCLL) enhancing apoptosis. J Nanobiotechnol. 2007;5:4.

16. Parashar V, Parashar R, Sharma B, Pandey AC. Parathenium leaf extract mediated synthesis of silver nanoparticles-a novel approach towards weed utilization. Digest Journal of Nanomaterials Biostructures. 2009; 4:45-50.

17. Chandran SP, Chaudhary M, Pasricha R, Ahmad A, Sastry M. Synthesis of gold nanotriangles and silver nanoparticles using aloevera plant extract. Biotechnol Prog. 2006;2:577-583.

18. Narayanan KB, Sakthivel N. Coriander leaf mediated biosynthesis of gold nanoparticles. Mater Lett. 2008; 62:4588-4590.

19. Kumar V, Yadav SK. Plant-mediated synthesis of silver and gold nanoparticles and their applications. J Chem Technol Biotechnol. 2009; 84:151-157.

20. Parashar V, Parashar R, Sharma B, Pandey AC. Parthenium leaf extract mediated synthesis of silver nanoparticles, a novel approach towards weed utilization. Digest Journal of Nanomaterials and Biostructures. 2009;4:45-50.

21. Narayanan KB, Sakthivel N. Coriander leaf mediated biosynthesis of gold nanoparticles. Mater Lett. 2008;62:4588-4590.

22. Huang J, Li Q, Sun D, et al. Biosynthesis of silver and gold nanoparticles by novel sundried Cinnamomum camphora leaf. Nanotechnology. 2007;18:105-104.

23. Gardea-Torresdey JL, Gomez E, Peralta-Videa JR, Parsons JG, Troiani H, Jose-Yacaman M. Alfalfa sprouts a natural source for the synthesis of silver nanoparticles. Langmuir. 2003:19: 1357-1361.

24. Li S, Shen Y, Xie A, et al. Green synthesis of silver nanoparticles using Capsicum annuum L. extract. Green Chem. 2007;9:852-858.

25. Armendariz V, Herrera I, Peralta-videa JR, et al. Size controlled gold nanoparticle formation by Avena sativa biomass use of plants in nanobiotechnology. J Nanopart Res. 2004;6:377-382.

26. Sharma NC, Sahi SV, Nath S, Parsons JG, Gardea-Torresdey JL, Pal T. Synthesis of plant- mediated gold nanoparticles and catalytic role of biomatrix-embedded nanomaterials. Environ Sci Technol. 2007;41: 5137-5142.

27. Mohanpuria P, Rana NK, Yadav SK. Biosynthesis of nanoparticles: technological concepts and future applications. J Nanopart Res. 2008; 10:507-517.

28. Lin XZ, Terepka AD, Yang H. Synthesis of silver nanoparticles in a continuous flow tubular microreactor. Nano Lett. 2004;4:2227-2232.

29. Leela A, Vivekanandan M. Tapping the unexploited plant resources for the synthesis of silver nanoparticles. Afr J Biotechnol. 2008;7: 3162-3165. 
30. Raut Rajesh W, Lakkakula Jaya R, Kolekar Niranjan S, Mendhulkar Vijay D, Kashid Sahebrao B. Phytosynthesis of silver nanoparticle using Gliricidia sepium (Jacq.). Curr Nanosci. 2009;5:117-122.

31. Xiaoming S, Liming Z, Songhua H. Amplified immune response by ginsenoside-based nanoparticles (ginsomes). Vaccine. 2009;27: 2306-2311.

32. Kasthuri J, Kathiravan K, Rajendiran N. Phyllanthin-assisted biosynthesis of silver and gold nanoparticles: a novel biological approach. J Nanopart Res. 2009;11:1075-1085.

33. Park HJ, Kim SH, Kim HJ, Choi SH. A new composition of nanosized silica-silver for control of various plant diseases. Plant Pathol J. 2006; 22:295-302.

34. Reninato M, Michelangeli FA, Goldenberg R. Phylogeny of Pleiochiton (Melastomataceae, Miconieae) total evidence. Bot J of the Linn Society. 2010;162:423-434.

35. Valko M, Leibfritz D, Moncol J, Cronin MT, Mazur M, Telser J. Free radicals and antioxidants in normal physiological functions and human disease. Int J Biochem Cell Biol. 2007;39:44-84.

36. Huang Y, Tan A, Shen Y, Lu J. Scavenging effect of total flavonoids of Lycium barbarum $L$ on active oxygen radicals and inhibitory effects on heat output from L 1210 cells. Wei Sheng Yen Chiu. 1998;27:109-111.

37. Young Jin K, Dongbum K, Younghee L, et al. Effects of nanoparticulate saponin-platinum conjugates on 2,4-dinitrofluorobenzene-induced macrophage inflammatory protein-2 gene expression via reactive oxygen species production in RAW 264.7 cells. BMP Reports. 2008;42:304-309.

38. Govindaraju K, Basha SK, Kumar VG, Singaravelu G. Silver, gold and bimetallic nanoparticles production using single-cell protein (Spirulina platensis) Geitler. J Mater Sci. 2008;43:5115-5122.

39. Sanoj Rejinolda N, Muthunarayanana M, Muthuchelianb K, Chennazhia KP, Shanti VN, Jayakumara R. Saponin-loaded chitosan nanoparticles and their cytotoxicity to cancer cell lines in vitro. Carbohydr Polym. 2011;84:407-416.
40. Ankamwar B, Chaudhary M, Sastry M. Gold nanotriangles biologically synthesized using tamarind leaf extract and potential application in vapor sensing. Synthesis and Reactivity in Inorganic, Metal-organic, and Nano-metal Chemistry. 2005;35:19-26.

41. Sathishkumar M, Sneha K, Won SW, Cho CW, Kim S, Yun YS. Cinnamon zeylanicum bark extract and powder mediated green synthesis of nano-crystalline silver particles and its bactericidal activity. Colloids Surf B Biointerfaces. 2009;73:332-338.

42. Shankar SS, Rai A, Ahmad A, Sastry M. Rapid synthesis of Au, Ag, and bimetallic Au core-Ag shell nanoparticles using Neem Azadirachta indica) leaf broth. J Colloid Interface Sc. 2004;275:496-502.

43. Dubay M, Bhadauria S, Kushwah BS. Green synthesis of nanosilver particles from extract of Eucalyptus hybrid (Safeda) Leaf. Dig J Nanomater Biostructures. 2009;4:537-543.

44. Rubio C, Casado C, Uriel S, Tellez C, Coronas J. Seeded synthesis of layered titanosilicate JDF-L1. Mater Lett. 2009;63:113-115.

45. Song JY, Jang HK, Kim BS. Biological synthesis of gold nanoparticles using Magnolia kobus and Diopyros kaki leaf extracts. Process Biochem. 2009;44:1133-1138.

46. Elumalai EK, Prasad TNVKV, Venkata K, Nagajyothi PC, David E. Green synthesis of silver nanoparticle using Euphorbia hirta $L$ and their antifungal activities. Archives of Appl Sci Research. 2010;2:76-81.

47. Song JY, Kim BS. Rapid biological synthesis of silver nanoparticles using plant leaf extracts. Bioprocess Biosyst Eng. 2009;32:79-84.

48. Garg HS, Bhakuni DS. 2',3'-Dehydrosalannol, a tetranortriterpenoid from Azadirachta indica leaves. Phytochemistry. 2001;24:866-867.

49. Siddiqui BS, Afshan F, Faizi GS, Naqvi SNH, Tariq RM. Two insecticidal tetranortriterpenoids rom Azadirachta indica. Phytochemistry (Oxford). Pakistan. Phytochemistry. 2000;53:371-376.
International Journal of Nanomedicine

\section{Publish your work in this journal}

The International Journal of Nanomedicine is an international, peerreviewed journal focusing on the application of nanotechnology in diagnostics, therapeutics, and drug delivery systems throughout the biomedical field. This journal is indexed on PubMed Central, MedLine, CAS, SciSearch $\AA$, Current Contents ${ }^{\circledR} /$ Clinical Medicine,

\section{Dovepress}

Journal Citation Reports/Science Edition, EMBase, Scopus and the Elsevier Bibliographic databases. The manuscript management system is completely online and includes a very quick and fair peer-review system, which is all easy to use. Visit http://www.dovepress.com/ testimonials.php to read real quotes from published authors. 